Case Report

\title{
Aneurysmal bone cyst of the lunate: Case report and literature review
}

\author{
André Sá Rodrigues *, Carlos Dopico, Rui Matos, Rui Pinto, Vitor Vidinha \\ Centro Hospitalar São João, Porto, Portugal
}

\section{A R T I C L E I N F O}

\section{Article history:}

Received 14 March 2016

Received in revised form 26 April 2016

Accepted 21 June 2016

Available online 8 July 2016

\begin{abstract}
A B S T R A C T
The aneurysmal bone cyst $(\mathrm{ABC})$ is a benign osteolytic bone neoplasm. Although most $\mathrm{ABC}$ is asymptomatic, in some cases they produce a mass effect, impinging against soft tissues or interfering with joint function. The authors present a rare case report of a lunate $A B C$ successfully treated by curettage and bone grafting, and review the literature of this pathology.
\end{abstract}

(c) 2016 Published by Elsevier, a division of Reed Elsevier India, Pvt. Ltd on behalf of Prof. PK Surendran Memorial Education Foundation.

\section{Background}

Wrist and hand aneurysmal bone cyst are rare, accounting for $6 \%$ of all bone tumors. ${ }^{1}$ Wrist pain of insidious onset, without trauma history, or acute pain due to a pathologic fracture, should raise suspicion of an $A B C$ in the carpus as a possible diagnosis. $^{2}$

\section{Case report}

A 50-year-old right-handed women, secretary, previously healthy, came to our office for evaluation of an insidious and crescent left (non-dominant) wrist pain with no trauma history, 6 months of duration and that progressively limited her daily activities.

Physical examination showed limited dorsiflexion of the wrist because of pain with tenderness over the scapholunate joint. No edema or major deformity was identified.

Antero-posterior and lateral radiographs and MRI of the patient's left wrist were performed, suggesting $A B C$ diagnosis (Figs. 1 and 2). Curettage of the lesion with bone grafting was proposed to the patient, as treatment.

Under sterile tourniquet and loupe magnification, a longitudinal and dorsal incision centered on the radiocarpal joint was performed (Lister's tubercle and 3rd metacarpal as references). No pathologic alterations were found while isolating the lunate bone

\footnotetext{
* Corresponding author at: Department of Orthopaedics, Centro Hospitalar São João, 4100 Porto, Portugal.

E-mail address: andresarodrigues@gmail.com (A. Sá Rodrigues).
}

(Fig. 3). A generous window on the dorsal cortex of lunate was made and bloody fluid coming from inside this bone was immediately identified (Fig. 4). Curettage with high-speed burring was used to clean all inner matter of the lunate bone (Fig. 5). Cancellous bone graft was harvested from the ipsilateral radius and impacted into the lunate, followed by soft tissue closure.

An antalgic volar wrist splint was applied for a period of 4 weeks. After that period of immobilization the patient attended a course of daily physical therapy during 1 month.

At 2 years follow-up, the patient was pain free. CT scan showed integration of bone graft (Figs. 6 and 7).

\section{Discussion}

Aneurysmal bone cyst ( $\mathrm{ABC}$ ), an osteolytic bone neoplasm, was first described by Lichtenstein in 1942 but until our days its etiology remains poorly understood. ${ }^{3}$ Some authors believe that they can occur when an arteriovenous malformation leads to blood-filled cystic formation and subsequent bone erosion. ${ }^{4}$ Histologic characteristics typical of $A B C$ are sponge-like blood or serum filled (normally non-endothelialized) spaces of various diameters. $^{1,5}$

$\mathrm{ABC}$ account for approximately 1-2\% of all bone tumors, appearing mostly in the metaphysis of long bones and the posterior elements of vertebral bodies. ${ }^{5,6}$ They are mainly seen in young people, with $80 \%$ occurring in patients with less than 20 years old. ${ }^{1,7}$

$A B C$ of the wrist and hand are very rare accounting for only $3-5 \%$ of all $A B C$, and most of the times affect metacarpals. ${ }^{8,9}$ To the best of our knowledge only 10 cases of $A B C$ in carpal bones have 


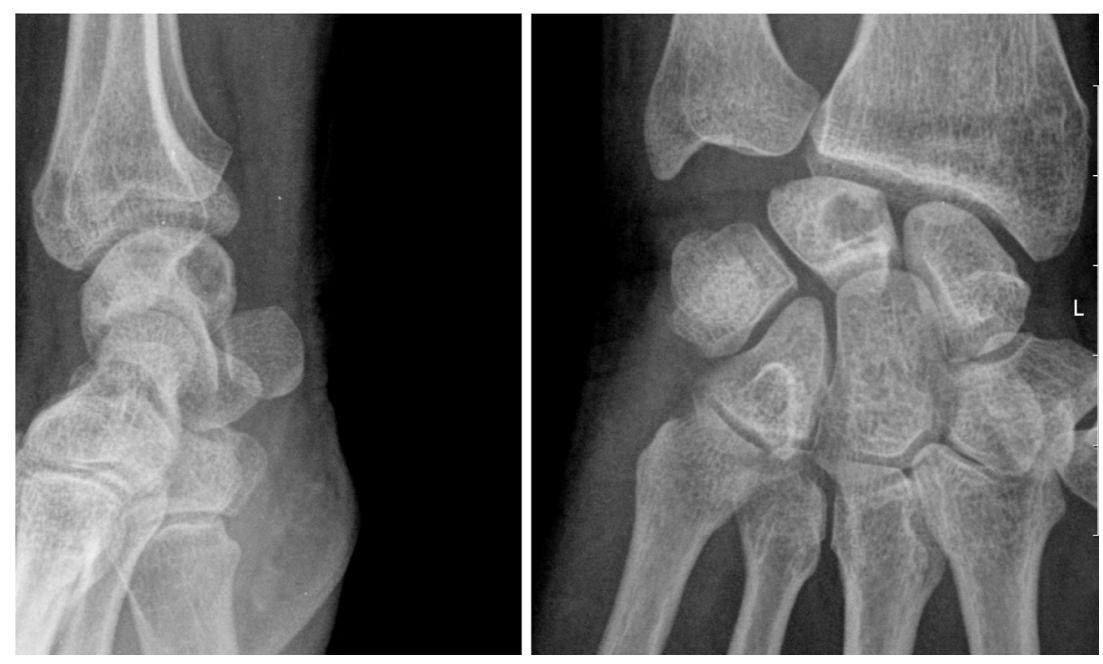

Fig. 1. First X-ray showing lunate lesion.

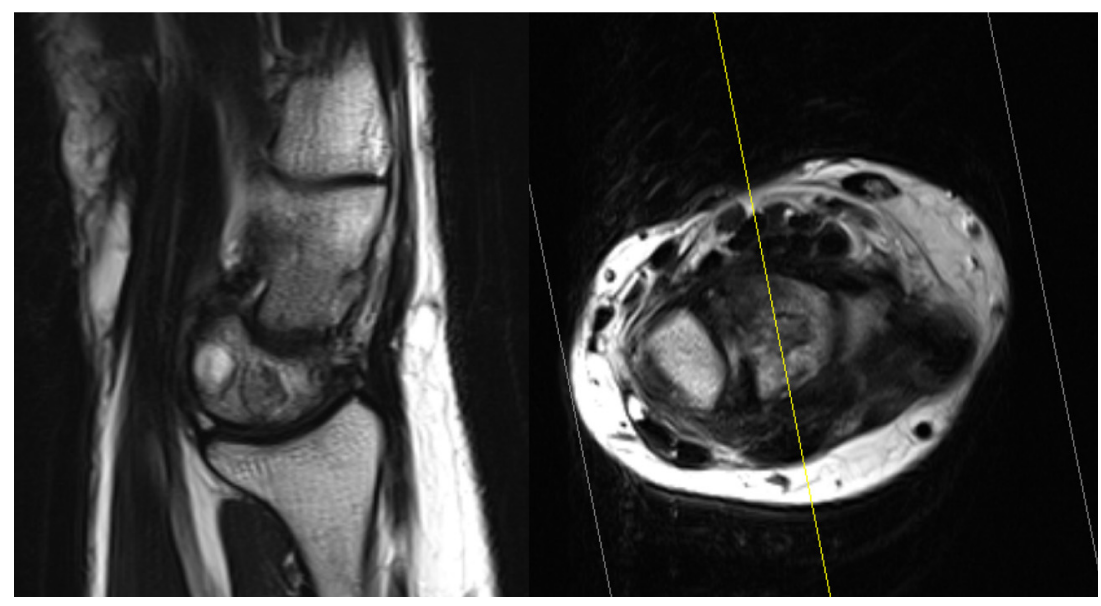

Fig. 2. MRI pre-operative showing lunate cyst lesion.

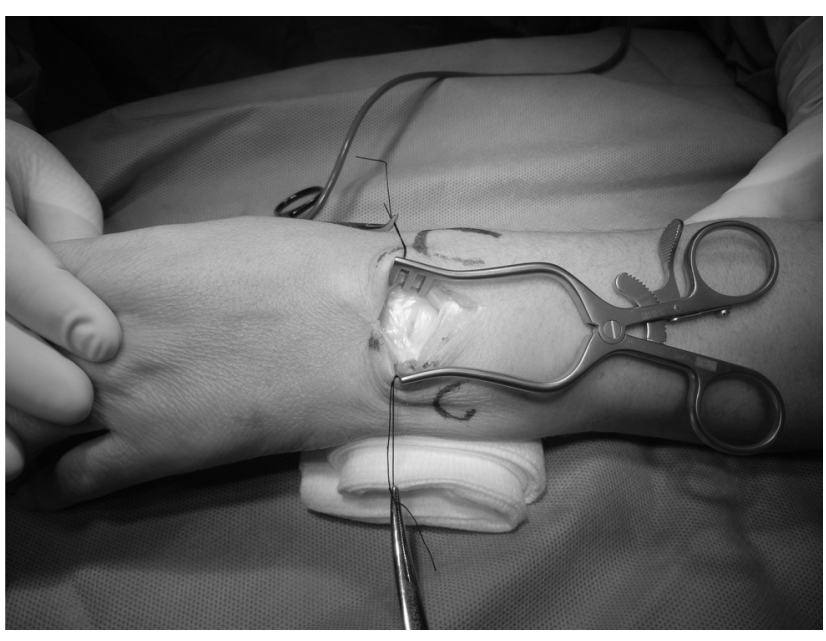

Fig. 3. Dorsal approach to lunate bone.

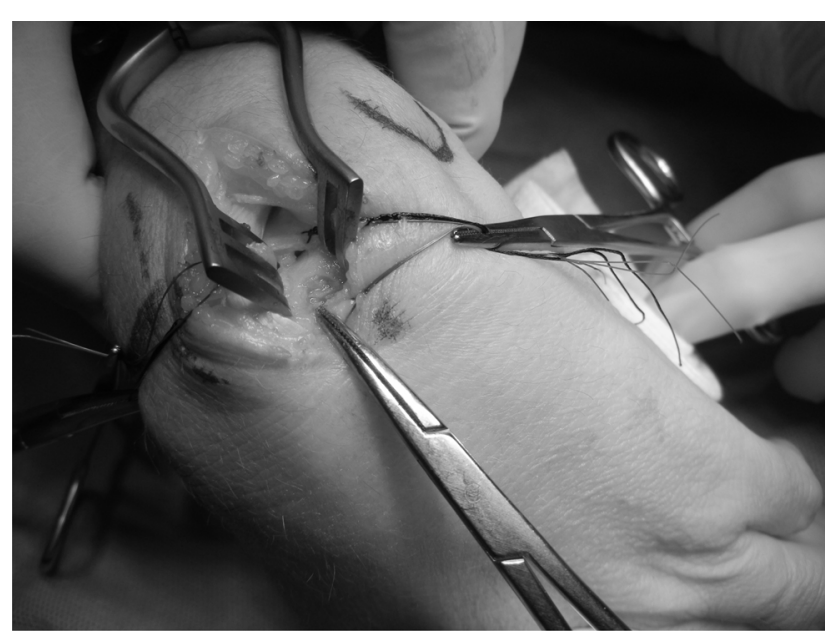

Fig. 4. Bloody fluid coming from inside of lunate after dorsal approach. 


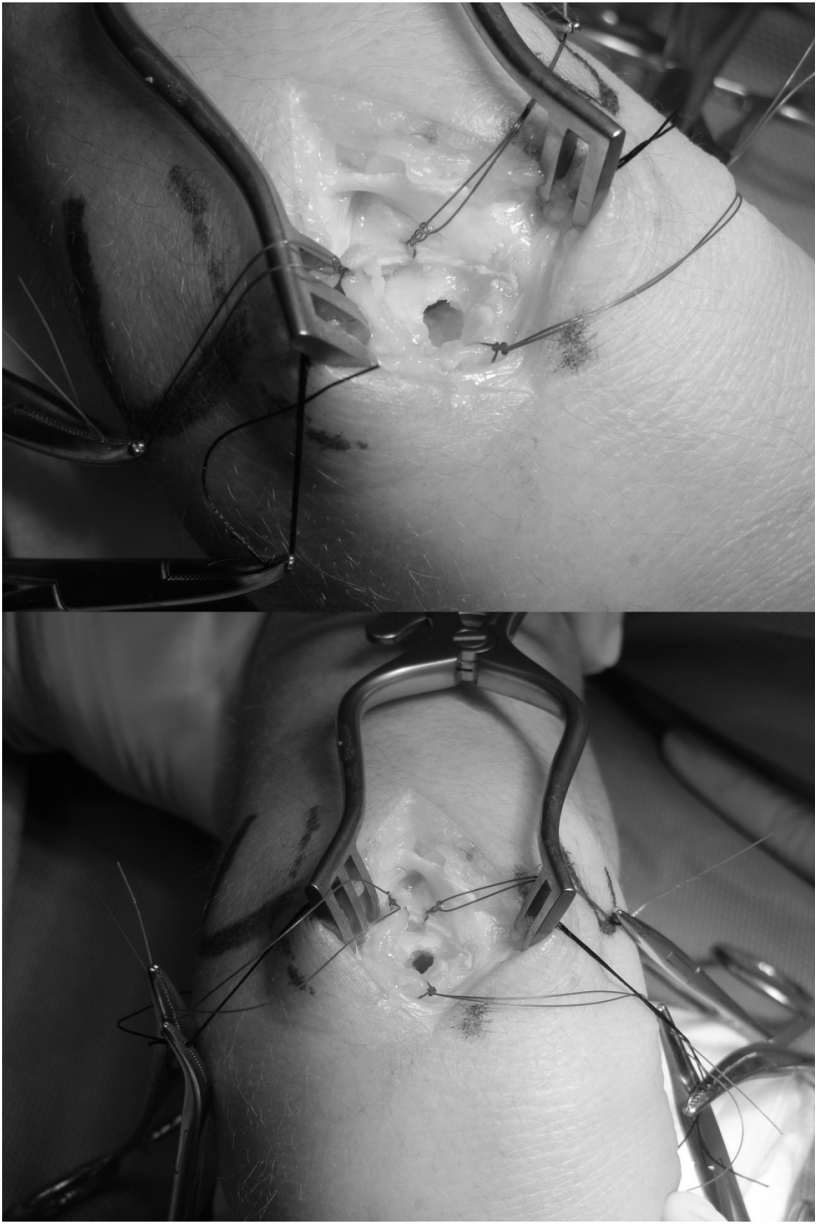

Fig. 5. Lunate after perform curetage with high-speed burring. Capsular reference for future closing.

been reported in scientific literature of which only 3 affected the lunate. ${ }^{10-12}$

Clinical presentation is nonspecific, with patients usually complaining of wrist pain of insidious onset without trauma history. Some refer acute pain onset due to a pathologic fracture. ${ }^{2,6}$

Although benign, ABC have a locally aggressive behavior, therefore early diagnosis is desired in the differential diagnosis of cystic lesions and wrist pain such as enchondroma, synovial cyst, Kienbock disease or giant cell tumors. ${ }^{1}$ Plain X-rays should initiate the diagnostic work-up if $A B C$ is suspected. ${ }^{2,10,11}$ In situations where X-rays suggests $A B C$, MRI usually clarifies the diagnosis. ${ }^{2,10}$ Needle biopsy is reserved for the few cases where doubt persists after MRI. ${ }^{2}$

The two main options described to treat carpal $A B C$ are bone resection and intralesional curettage. ${ }^{6,13-15}$ In the presence of cartilage damage, excision followed by intercarpal arthrodesis or a resection of the first row of the carpus is recommended. ${ }^{10}$

Mankin et al. performed a resection of the lunate with a scaphocapitate arthrodesis which lead to a limited wrist range of motion. ${ }^{11}$ Rajappa et al. performed a resection of the lunate without carpal fusion with good functional results but with a high risk of progressive degenerative changes in the future. ${ }^{12}$

On the other hand, Moussallem et al. performed curettage and iliac autologous bone grafting of an $A B C$ of the lunate with good clinical results and no recurrence. ${ }^{10}$

Previous papers showed a high recurrence rate after this kind of treatment on other bones. Frassica et al. showed that 4 out of 7 patients treated to $\mathrm{ABC}$ in the hand with intralesional curettage had recurrence. ${ }^{6}$ Mankin et al. also noted a $20 \%$ recurrence in a group of 150 patients treated to $\mathrm{ABC}$ over all the skeleton. ${ }^{16}$

However, Crowe et al. presented a series of 11 hand $A B C$ treated with curettage and grafting and reported only 1 recurrence. They postulated that their favorable outcomes resulted from: (1) making a large enough bone window that allowed an aggressive curettage and that reached all recesses of the lesion; (2) complementation of curettage with mechanical, chemical or thermal adjuvants; (3) use of bone graft. ${ }^{2}$

As suggested by Makin et al. overall recurrence after $A B C$ treatment usually appears at $1.2 \pm 0.7$ years. Frassica et al. and Crowe et al. showed that $A B C$ recurrence after curettage and bone grafting was observed before the first year. ${ }^{2,6,16}$ In our case study, the patient had no symptoms or signs of recurrence at 2 years follow-up, which supports previous opinions that defend this treatment as first option for symtomatic lesions without cartilage damage.

This is the first report of a lunate $A B C$ treated with curettage and bone autografting from ipsilateral radius. Regardless of the low number of reported cases, the authors also believe that performing an aggressive curettage and bone autografting of the lunate minimizes morbidity and preserves wrist function in the cases that cartilage is not damaged, which is an advantage to the complete surgical excision of the affected bone.

The prognosis of $A B C$ in the carpal bones seems to be favorable regardless the use of distinct bone grafts or bone substitutes. ${ }^{2,13}$ We believed that using radius autograft brings more benefits since it is associated with lower morbidity of the donator area, making possible to do this treatment in an outpatient regime.

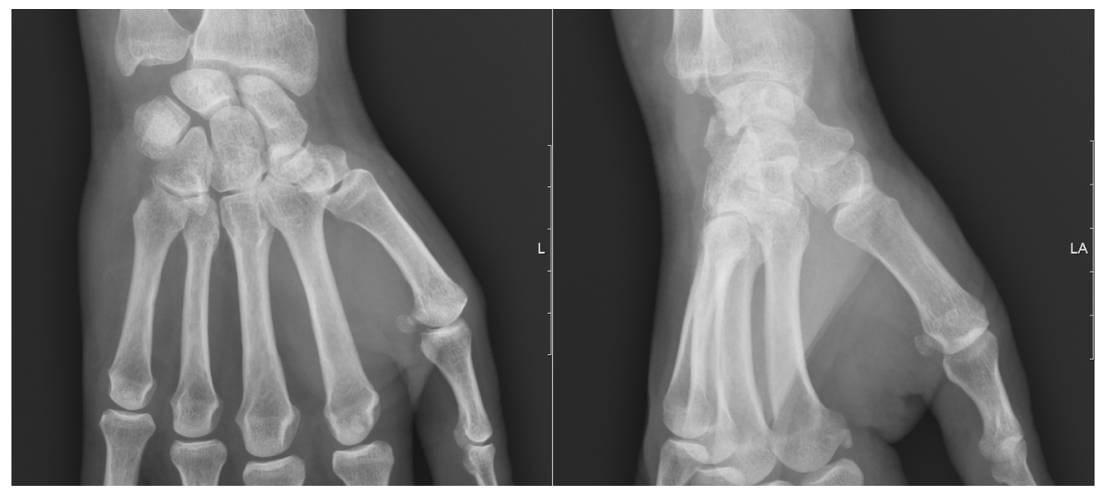

Fig. 6. X-ray 6 month post-op. 

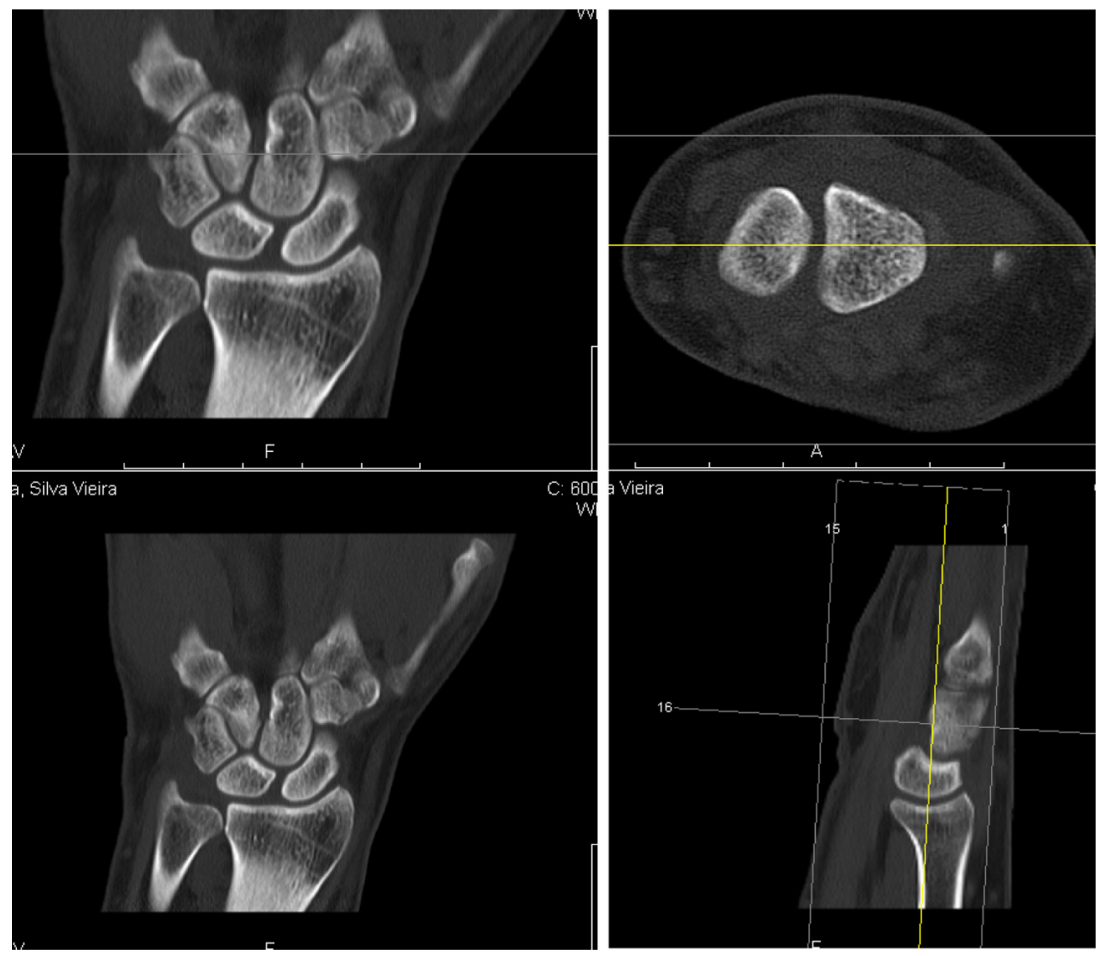

Fig. 7. CT scan after 1 year post-op.

\section{Conflicts of interest}

The authors have none to declare.

\section{References}

1. Leithner A, Windhager R, Lang S, Haas OA, Kainberger F, Kotz R. Aneurysmal bone cyst. A population based epidemiologic study and literature review. Clin Orthop Relat Res. 1999;363:176e179.

2. Crowe MM, Houdek MT, Moran SL, Kakar S. Aneurysmal bone cysts of the hand, wrist, and forearm. J Hand Surg. 2015;40(10):2052-2057.

3. Lin E, Engel J, Bubis JJ, Herman O. Aneurysmal bone cyst of the hamate bone. J Hand Surg. 1984:9A:847-850.

4. Mortensen NH, Kuur E. Aneurysmal bone cyst of the proximal phalanx. J Hand Surg. 1990;9(15B):482-483.

5. Rapp TB, Ward JP, Alaia MJ. Aneurysmal bone cyst. J Am Acad Orthop Surg. 2012;20(4):233e241.

6. Frassica FJ, Amadio PC, Wold LE, Beabout JW. Aneurysmal bone cyst: clinicopathologic features and treatment of ten cases involving the hand. J Hand Surg Am. 1988;13(5):676e683.
7. Fletcher CDM. Pathology and Genetics of Tumours of Soft Tissue and Bone. Geneva: World Health Organization; 2002:338-339.

8. Platt AJ, Klugman DJ. Aneurysmal bone cyst of the capitate. 1995;20B:8-11.

9. Johnston AD. Aneurysmal bone cyst of the hand. Hand Clin. 1987;299-310.

10. Moussallem CD, Arnalsteen DM, Khlifi H, Blanpain S, Mertl P, Gabrion A. Aneurysmal bone cyst of the lunate: case report. J Hand Surg Am. 2011;36A: 106-109.

11. Mankin KP, Bischoff RJ, Gelberman RH, Rosenberg AE. Aneurysmal bone cyst involving the lunate. J Hand Surg. 1995;9(20B):12-15.

12. Rajappa S, Kumar MM. Aneurysmal bone cyst of lunate treated by excision without intercarpal fusion: a case report. J Hand Surg. 2013;38(9).

13. Sakamoto A, Tanaka K, Matsuda S, Oda Y, Tsuneyoshi M, Iwamoto Y. Aneurysmal bone cyst of the capitate: case report and a review emphasizing local recurrence. Fukuoka Igaku Zasshi. 2006;97:302-307.

14. Bogar WC. Aneurysmal bone cyst of the hand. J Manip Physiol Ther. 1993;16(3): $182 \mathrm{e} 184$.

15. Chalmers J. Aneurysmal bone cysts of the phalanges. A report of three cases. Hand. 1981;13(3):296e300

16. Mankin HJ, Hornicek FJ, Ortiz-Cruz E, Villafuerte J, Gebhardt MC. Aneurysmal bone cyst: a review of 150 patients. J Clin Oncol. 2005;23(27):6756e6762. 